\title{
Heat tracer test in an alluvial aquifer: field experiment and inverse modelling
}

Maria Klepikova (1), Samuel Wildemeersch (2), Pierre Jamin (2), Philippe Orban (2), Thomas Hermans (3), Frederic Nguyen (4), Serge Brouyère (2), and Alain Dassargues (2)

(1) ETH Zurich, Zurich, Switzerland (maria.klepikova@erdw.ethz.ch), (2) University of Liege, ArGEnCo, Hydrogeology and Environmental Geology Unit, Liege, Belgium, (3) Department of Geological Sciences, Stanford University, (4) University of Liege, ArGEnCo, Applied Geophysics Unit, Liege, Belgium

Using heat as an active tracer for aquifer characterization is a topic of increasing interest. In this study, we investigate the potential of using heat tracer tests for characterization of a shallow alluvial aquifer. A thermal tracer test was conducted in the alluvial aquifer of the Meuse River, Belgium. The tracing experiment consisted in simultaneously injecting heated water and a dye tracer in a piezometer and monitoring the evolution of groundwater temperature and tracer concentration in the recovery well and in monitoring wells. To get insights in the $3 \mathrm{D}$ characteristics of the heat transport mechanisms, temperature data from a large number of observation wells distributed throughout the field site (space-filling arrangement) were used.

Temperature breakthrough curves in observation wells are contrasted with what would be expected in an ideal layered aquifer. They reveal strongly unequal lateral and vertical components of the transport mechanisms. The observed complex behavior of the heat plume was explained by the groundwater flow gradient on the site and heterogeneity of hydraulic conductivity field. Moreover, due to high injection temperatures during the field experiment a temperature-induced fluid density effect on heat transport occurred. By using a flow and heat transport numerical model with variable density coupled with the pilot point inverse approach, main preferential flow paths were delineated. 